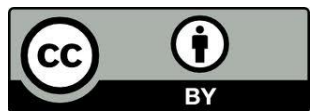

\title{
A JUVENTUDE CARÍSMÁTICA DE LONDRINA: MEIOS DE APROXIMAÇÃO COM O MOVIMENTO ${ }^{1}$
}

\author{
The Charismatic Youth of Londrina: The Approaching With The Moviment
}

\author{
Douglas Alexandre Boschini \\ Universidade Estadual de Londrina \\ Doutorando do Programa de Pós-Graduação em Serviço Social e Política Pública \\ douglasboschini@gmail.com \\ Claudia Neves da Silva \\ Universidade Estadual de Londrina \\ Professora Associada do Dpto de Serviço Social e \\ do Programa de Pós-Graduação em Serviço Social e Política Pública \\ Doutora em História Social pela UNESP/Assis \\ claudianevess@uel.br
}

RESUMO: O presente artigo tem por objetivo discutir as relações entre a Renovação Carismática Católica e a juventude participante dos grupos de oração na cidade de Londrina - PR. Desde sua origem, a RCC demostrou interesse na juventude, suas ações e atividades costumam em geral ser desenvolvidas de modo a agradar e consequentemente agregar os jovens católicos. A Renovação Carismática Católica trouxe consigo maiores possibilidades e espaços para a atuação dos fiéis, proporcionando a eles uma sensação de maior participação e poder de ação, deixando de exigir somente a crença e a obediência como ocorria/ocorre nos ritos tradicionais das missas católicas, mas utilizando de maneiras diferentes a capacidade de interação de seus fiéis. Para compreender o caminho pelo qual a juventude se junta a este movimento foram realizadas entrevistas com jovens integrantes do movimento carismático de Londrina, já que este se tornou um importante fator de agregação da juventude, que permitiu a busca por uma identidade que possa defini-los ao mesmo tempo em que possa ser compartilhada.

Palavras chave: Renovação Carismática Católica; Juventude; Identidade.

ABSTRACT: This article aims to discuss the relations between the Catholic Charismatic Renewal and the participating youth of the prayer groups in the city of Londrina - PR. Since its origin the CCR has shown strong interest in youth, their actions and activities tend in general to be developed in order to please and consequently add young Catholics. The Catholic Charismatic Renewal has brought greater opportunities and spaces for the actions of the faithful, giving them a greater sense of participation and power of action, leaving only require belief and obedience as was / is the traditional rites of the Catholic masses, but using different ways the ability of interaction of the faithful. This being one of the main youth aggregation factors, which allowed the search for an identity that can set them at the same time it can be shared.

Keywords: Catholic Charismatic Renewal; Youth; Identity.

${ }^{1}$ Este artigo origina-se da dissertação de mestrado sob orientação do professor pós-doutor Fabio Lanza, apresentada ao Programa de Pós-Graduação em Ciências Sociais da Universidade Estadual de Londrina 


\section{Introdução}

A Renovação Carismática Católica (RCC) é um movimento da Igreja Católica que surgiu nos Estados Unidos no ano de 1967, a partir de um retiro espiritual realizado na Universidade de Duquesne e chegou ao Brasil em 1969, inicialmente na cidade de Campinas, interior do Estado de São Paulo. Em seu desenvolvimento, a RCC no Brasil demonstrou interesse pela juventude, tornando-os público alvo de suas ações, neste artigo será trabalhado os meios de aproximação e de contato deste movimento com os jovens em Londrina - PR.

Tendo por objetivo compreender o caminho pelo qual a juventude se une/agrega a este movimento foram realizadas entrevistas com jovens integrantes do movimento carismático de Londrina, e, por meio das falas dos sujeitos, analisar as maneiras e os caminhos de contato com a RCC.

\section{A RCC no Brasil e a Juventude Católica}

Para Brenda Carraza (2000), a Renovação Carismática Católica chegou ao Brasil no ano de 1969 na cidade de Campina - SP, com a vinda de dois padres jesuítas, Haroldo Rahm e Eduardo Dougherty. Da mesma forma que o livro A Cruz e o Punhal de David Wilkerson impulsionou o Movimento Carismático nos Estados Unidos, o livro Sereis Batizado no Espírito de 1972, aprovado pela CNBB legitimou e alavancou a difusão da RCC no Brasil. Esta obra possui grande importância uma vez que é a partir dela que foram realizados diversos seminários e retiros espirituais - que contavam com a participação de sacerdotes norte-americanos -, como Experiência do Espírito Santo e posteriormente Experiências de Oração, servindo como primeiro meio de promoção e ampliando sua divulgação, já que os fiéis que estavam presentes nos encontros convidavam demais conhecidos a participarem.

A atuação da RCC está centrada principalmente nos chamados Grupos de Oração, Reginaldo Prandi (1998) afirma que desde seu início, o movimento carismático alcançou um considerável número de seguidores, entretanto, como aponta Cecília Mariz (2004) foi somente a partir da segunda metade da década de 1990 que entra de fato em seu período de maior crescimento, a partir da conquista de meios de comunicação social 
pela aquisição de canais de televisão e estações de rádio, como a Canção Nova, e também pelo ramo editorial, produzindo livros e apostilas utilizados nos encontros.

A conquista dos meios de comunicação social é, inegavelmente, um aspecto de extrema importância para a compreensão do crescimento e desenvolvimento da RCC no Brasil, pois a partir de uma análise de suas ações torna-se possível encontrarmos o seu grupo de fiéis e vice e versa. Para Carranza (2000) o corpo de fiéis deste movimento está composto principalmente pela população urbana, justamente a parcela populacional que caracteriza-se enquanto maior consumidora das mídias, seja impressa, televisiva ou sonora. Esta conquista representa um reconhecimento da grande força das mídias mediante as novas realidades sociais e os novos hábitos da população, possibilitando maior alcance àqueles que as consome diariamente.

Portanto, com a criação de canais de televisão e estações de rádio próprias, a Renovação Carismática Católica conseguiu inserir-se na vida cotidiana da população em espaços até então extra religiosos, tornando possível o consumo de seus conteúdos em diversos momentos do dia, seja indo ao trabalho, à escola ou mesmo em casa, assistindo televisão, aumentando assim, o contato com os indivíduos e ampliando a sua capacidade de evangelização, catequização e, consequentemente, o número de fiéis, em especial a juventude, que constitui o principal público consumidor dessas mídias.

Faz-se necessário ressaltar que a utilização dos meios de comunicação social não auxilia somente no processo de evangelização e conquista de novos adeptos, mas também, ao fazer-se presente inúmeras vezes no cotidiano dos fiéis, acabam por fortalecer o contato destes com a Igreja, servindo também para frear a perda de católicos gerada pelo trânsito religioso.

O enfoque na população jovem não se apresenta enquanto característica exclusiva da Renovação Carismática Católica, em denominações neopentecostais e pentecostais também são encontradas atividades e grupos com apelo à juventude, um exemplo deste fato é a Jornada Mundial da Juventude, sediada pelo Brasil no ano de 2013, apesar de ser um evento católico, diversos grupos jovens de denominações pentecostais e neopentecostais marcaram presença no evento. Para serem melhor trabalhadas as relações da Renovação Carismática Católica com os jovens faz-se necessário delimitar a que nos referimos quando dizemos juventude. 
E quem são “eles"? São aqueles nascidos há 14 ou 24 anos seria uma resposta. No entanto, esses limites de idade também não são fixos. Para os que não têm direito à infância, a juventude começa mais cedo. E, no outro extremo - com o aumento de expectativas de vida e as mudanças no mercado de trabalho -, uma parte "deles" acaba por alargar o chamado "tempo da juventude" até a casa dos 30 anos. Com efeito, qualquer que seja a faixa etária estabelecida, jovens com idades iguais vivem juventudes desiguais. (NOVAES, 2006, p. 105.)

Delimitar uma faixa etária para classificar a juventude apresenta-se enquanto uma difícil tarefa, sendo mutável e flexível dependendo de qual juventude está sendo abordada. Portanto, para realizar tal tarefa, são utilizadas as definições legais, que segundo o Estatuto da Juventude (Lei 12.852/13), em seu artigo primeiro, parágrafo primeiro, considera jovem, a pessoa com idade entre quinze e vinte e nove anos.

De certo modo é possível afirmarmos que os jovens estão em uma posição intermediária na sociedade, já superaram a infância, recebendo maiores responsabilidades, liberdades, ao mesmo tempo não são considerados adultos, mas são cobrados atitudes e comportamentos similares, portanto podemos pensar a juventude enquanto uma fase de transição. É justamente neste espaço intermediário que são criadas e recriadas as culturas jovens, fazendo emergir signos de reconhecimento e de identidades.

Em uma sociedade plural como a brasileira não é possível encontrarmos uma identidade única e homogênea, mas é fato que independente da identidade dos grupos juvenis a juventude encontra-se em um constante processo de elaboração de valores e concepções para interpretar o mundo, sendo que os ideais dos grupos aos que pertencem possuem elementos formadores de opinião.

A formação de grupos caracteriza-se enquanto importante elemento para a compreensão a respeito da juventude e de seus comportamentos, sendo que suas características estão diretamente vinculadas à própria sociedade.

Para entender as mudanças ocorridas no perfil da juventude nos últimos anos, é necessário compreender as mudanças da própria sociedade brasileira, principalmente no que tange a questão educacional, trabalhista e política. Parte-se do pressuposto que os espaços privilegiados pela juventude para participação na sociedade foram mudando conforme o desenvolvimento 
histórico, sendo que nos anos 1960 e 1970 havia o predomínio do sindicato e movimento estudantil, nos anos 1980 nos movimentos sociais e nos anos 1990 os jovens atuam de forma diluída e fragmentada nos movimentos culturais e lúdicos. (SOFIATI, 2008, p. 3-4)

Contudo, nos anos 2000 os movimentos religiosos, em especial a Renovação Carismática Católica e os Pentecostais do meio protestante brasileiro, tem se apresentado enquanto um grande espaço de socialização para a juventude, neste sentido a Renovação Carismática Católica trouxe, para o catolicismo brasileiro, diversas novas propostas de prática e atuação da Igreja, que viriam a modificar definitivamente as formas de suas ações.

Dentre as transformações trazidas pela Renovação Carismática Católica, não há como negar que os Grupos de Oração - seu principal espaço de atuação - apresentam-se enquanto uma das mudanças mais radicais na Igreja, considerando que antes o papel evangelizador era reconhecido aos padres e os mesmos ficavam responsáveis pela organização das atividades de sua paróquia. Já com a RCC, os Grupos de Oração são coordenados e executados por lideranças religiosas leigas, ou seja, pelos fiéis, que se tornaram responsáveis por evangelizar nestes espaços e organizar tanto os debates quanto as atividades.

Os Grupos são apresentados aos jovens enquanto espaços de livre expressão, nos quais os fiéis encontram a oportunidade de além de orar, falar e debater questões a respeito das angústias e insatisfações com o cotidiano e os novos estilos de vida. Tal liberdade atua de forma a proporcionar a seus integrantes uma sensação de acolhimento e um clima de fraternidade que acaba por criar os laços afetivos existentes em uma comunidade religiosa, gerando no jovem uma sensação de reconhecimento e aceitação de sua personalidade, o que lhe oferece um sentimento de pertencimento.

São organizados e divididos de acordo com o público, realizando encontros semanais, portanto em uma mesma paróquia, dependendo do perfil dos fiéis, são encontrados grupos de casais, de adolescentes, de jovens, etc.. Nos encontros dos grupos é ofertada aos fiéis a possibilidade de experimentar de forma efusiva a religiosidade, através do louvor, da música e da adoração proporcionando aos participantes o exercício dos dons carismáticos, o repouso no espírito, assim como o que chamam de um contato com Jesus. 
[...] É no grupo de oração que o ponto alto da vida carismática é experimentado: nos grupos de oração as pessoas podem vivenciar as mais diversas formas de adoração e louvor. E é louvar o que realmente interessa. Ali as pessoas podem cantar, pular, extravasar as tenções, trocar calor, sentir-se importantes. Além disso, é nos grupos de oração que todos recebem as bênçãos que Jesus lhes pode dar. (PIERUCCI e PRANDI, 1996, p. 66)

Nas sociedades modernas o trabalho consome grande parte do tempo dos indivíduos e as novas formas de vida trouxeram o sentimento de isolamento. A nova rotina acaba por diminuir os horários destinados ao lazer, assim como o crescimento dos índices de violência urbana gera um enclausuramento das pessoas em suas próprias casas e um medo constante, além de uma sensação de anonimato.

Portanto, os grupos de oração, com os louvores, as músicas, os debates, etc. proporcionam aos fiéis espaços de libertação de seus medos, de socialização com os demais, uma vez que cria uma comunidade religiosa em que o próximo é tido como amigo e de momentos para liberar todas as angústias resultantes do dia-a-dia. Os grupos de oração representam para este movimento católico o seu local de evangelização, e nas reuniões, ao serem debatidas as ocorrências do cotidiano, são trabalhadas, também, as melhores formas de enfrentamento das realidades de vida de seus membros.

O espaço oferecido pela Renovação Carismática Católica para a exposição de problemas pessoais proporciona aos fiéis um local onde os mesmos sentem-se importantes e reconhecidos e é justamente esta sensação que gera o sentimento de pertencimento, que acaba por gerar laços afetivos responsáveis pela preservação da participação dos membros na Igreja, além de fazer com que os fiéis trabalhem em um sentido de agregar novos integrantes, convidando seus conhecidos a participarem, também, dos encontros. O convite, isto é, esta divulgação "boca a boca" caracterizou-se como principal fonte de divulgação da Renovação Carismática Católica.

Como já foi mencionado, um dos principais elementos que caracterizam a Renovação Carismática Católica consiste na promoção de eventos e encontros, que ocorrem para além dos espaços físicos das igrejas em si, sendo os Cenáculos um desses exemplos - o nome faz menção ao local em que encontravam-se os apóstolos no dia de 
pentecostes, definido como o dia em que os mesmos vivenciaram um contato com o Espírito Santo, de acordo com o Novo Testamento.

Os cenáculos realizados pela Renovação Carismática Católica consistem em eventos anuais organizados com o intuito de promover experiências de oração e o encontro dos integrantes de diversos Grupos de Oração, e sua programação inclui momentos de fala para pregadores e a apresentação de bandas de música Católica.

Os carismáticos também se reúnem em grandes encontros anuais, os cenáculos, que acontecem em lugares públicos de grande visibilidade, normalmente ginásios ou estádios. Na cidade de São Paulo, aos moldes das grandes igrejas pentecostais, a RCC aluga o estádio do Morumbi para que lá possa demonstrar a sua força; o cenáculo é uma demonstração de força, como eram as velhas procissões. Mais de cem mil pessoas têm participado desses encontros em São Paulo. (PIERUCCI e PRANDI, 1996, p. 66)

Um dos principais atrativos da RCC é a questão do pertencimento, eventos como os cenáculos que promovem uma grande socialização revelam possuir um alto poder de eficácia para com a juventude. Apesar dos Cenáculos constituírem-se em encontros religiosos, os mesmos apresentam-se, também, enquanto espaços voltados para o entretenimento dos fiéis, contando com apresentações de diversas bandas de gospel católico e atividades que visam proporcionar certa diversão aos participantes.

Diversos eventos promovidos pela Renovação Carismática Católica são organizados com o intuito de oferecer espaços de diversão e socialização para os jovens, como os "barzinhos de Jesus", onde os fiéis encontram a chance de interagirem, socializarem e se divertirem ao som de músicas religiosas nos mais variados estilos musicais, rock, heavy metal, samba etc.

Um elemento que tem sido amplamente utilizado pelas instituições religiosas contemporâneas é a música e a Renovação Carismática Católica se utiliza desta ferramenta desde seu começo no Brasil - o Padre Marcelo Rossi é um exemplo. Juntamente com o crescimento da RCC, diversas bandas de gospel católico têm surgido, produzindo músicas específicas para seu público de fiéis e apresentando-se em seus eventos. Estas bandas comumente possuem nomes que fazem referências a Israel, como Rosa de Sharon, El Shaddai, etc., seus repertórios musicais abrangem quase que a 
totalidade rítmica em estilos musicais, com letras vinculadas ao catolicismo e sua doutrina, abordando questões a respeito da vida, de conversão, castidade e outros.

Esses espaços ao mesclarem momentos de descontração e diversão, com intervenções para oração e pregação, proporcionam momentos de fácil disseminação dos valores e ideais carismáticos, uma vez que são compostos por duas etapas, a primeira em que um testemunho é ouvido, normalmente a respeito de conversão e mudança de estilo de vida e logo em seguida um discurso é realizado pelo pároco acerca do comportamento dos jovens, em meio a músicas, risadas e conversas.

O novo conjunto de práticas, rituais e espaços utilizados pela RCC, que modernizaram as formas de atuação da Igreja, têm por objetivo principal a ampliação de seu projeto evangelizador. São utilizados como ferramentas com o intuito de atrair novos fiéis e agradar o seu corpo de praticantes. Portanto, os cenáculos, os grupos de oração, barzinhos de Jesus e os demais eventos e práticas religiosas apresentam-se de forma coerente ao projeto modernizador da Renovação Carismática Católica, pautado nas determinações e orientações do Concílio Vaticano II, demonstrando o interesse deste movimento pela juventude.

\section{A juventude carismática de Londrina}

Com o intuito de estudar as formas de aproximação do movimento carismático com a juventude e compreender o que é buscado e encontrado pelos jovens, foram realizadas observações de campo em encontros de grupos jovens de oração da cidade de Londrina - PR e entrevistas com coordenadores dos grupos que se enquadravam, também, no perfil etário da pesquisa.

A Renovação Carismática Católica apresenta-se enquanto um movimento fortemente hierárquico, com diversas secretarias, coordenações, ministérios, arquidioceses e dioceses, estando dividida em níveis: mundial, nacional, estadual e municipal. No Estado do Paraná, segundo informações do sítio da Renovação Carismática Católica do Paraná, há a divisão em quatro províncias, com uma sede arquidiocesana em cada, sendo Cascavel, Curitiba, Maringá e Londrina responsáveis pelas dioceses de suas regiões. 
A Arquidiocese de Londrina encontra-se responsável pelas dioceses de Apucarana, Cornélio Procópio e Jacarezinho, que por sua vez são responsáveis pelas demais cidades das regiões. A Arquidiocese de Londrina está dividida por decanatos, que são responsáveis pela coordenação de suas regiões, são estes: Centro, Norte, Sul, Leste, Oeste; as cidades de: Cambé, Sertanópolis, Tamarana, Rolândia, Porecatu e Ibiporã, ficando cada decanato responsável por coordenar os grupos e as ações de sua região.

No tocante aos grupos de oração, de acordo com o sítio RCC Brasil, a Arquidiocese de Londrina tem cadastrado um total de cento e quinze grupos de oração, sendo trinta e três destes grupos de jovens, referentes a todos seus decanatos, constando apenas setenta e nove grupos no sítio da RCC Londrina. Entretanto, estima-se que o número real vai além dos cento e quinze grupos, uma vez que o cadastro é feito pelos próprios e muitos deles não o realizaram.

Os grupos de oração estão, também, localizados fora dos domínios paroquiais, encontrados dentro das universidades, ação empreendida pelo ministério de Universidades Renovadas. Foram encontrados onze grupos de oração universitários, dez em Londrina, sendo três na Universidade Estadual de Londrina, realizando seus encontros na Capela Ecumênica e na Clínica Odontológica. Os demais estão presentes na Universidade do Norte do Paraná (UNOPAR), em seus três campi, PUC, Pitágoras, UNIFIL, INESUL e Faculdade Catuaí, localizada na cidade de Cambé.

Os grupos de oração universitários são capazes de alcançar os fiéis que não estão vinculados a uma paróquia, considerando que muitos dos estudantes universitários mudam-se de suas cidades para Londrina para estudar, além de marcar a presença em um espaço laico e dedicado à ciência.

Pela observação tornou-se possível perceber que os encontros dos grupos de oração estão estruturados por normas determinadas pelo próprio movimento, possuindo poucas alterações entre um grupo e outro.

As reuniões ocorrem em sua maioria aos finais de semana, principalmente aos sábados à noite, nos grupos observados havia sempre uma média de vinte a trinta jovens, com exceção do grupo da zona sul, que continha mais de cinquenta pessoas. Os encontros normalmente são realizados nos salões paroquiais anexos às igrejas, usualmente antes ou depois da realização da missa. Os encontros de oração são 
organizados pelos coordenadores de cada grupo em conjunto com os servos, sendo estes, aqueles fiéis que passaram por processos de formação e integram os ministérios.

Com a observação de campo foi possível constatar a presença de um dos principais elementos de atração da RCC, a socialização. Em todos os grupos observados, os jovens se reuniram antes do começo do encontro para conversarem a respeito da sua semana e diversos outros assuntos não relacionados à religião, momentos nos quais aproveitavam para rir e falar de seus problemas com os demais participantes, além de combinarem atividades pessoais, como ir ao shopping, assistir um filme etc.

Os momentos de interação prévios ao início dos encontros também são utilizados de forma racional pela Renovação, com o intuito de iniciar seu trabalho. Alguns jovens ficam encarregados pela acolhida, ou seja, ficam atentos caso haja um participante novo, se houver, dirigem-se a ele para conversar, recebê-lo e descobrir os motivos que o levaram a procurar o grupo. Os jovens responsáveis pela acolhida ficam nas portas no início das reuniões, para cumprimentar e receber os integrantes dos grupos.

É possível destacarmos que o momento de acolhida anterior ao encontro dos grupos é utilizado de forma a receber e conhecer novos participantes e descobrir as razões que o levaram ao grupo, tal conhecimento facilita a relação dos coordenadores dos grupos com os novos participantes e até lhes mune para maior aproximação com os possíveis novos integrantes.

Entretanto, a acolhida não é vista neste trabalho somente como uma ferramenta utilizada para levantar dados a respeito dos novos participantes, possui outro elemento que melhor agrada o fiel: o momento da acolhida aparece ao jovem enquanto um convite, uma aceitação do grupo. Assim, ao chegar ao encontro de um grupo, o jovem encontra semelhantes que o vêm e começam a conversar e demonstrar interesse por ele, com a intenção de mostrar que lá ele é bem vindo. Utilizando do ditado popular "a primeira impressão é a que fica", ao ir a um grupo de oração a primeira impressão dada aos jovens é de que naquele espaço eles são bem vindos e aceitos, que todos os querem lá, oferecendo aos jovens a sensação de que sua presença é importante para o grupo.

Os encontros dos grupos de oração seguem uma mesma estrutura, início das reuniões com o acolhimento e a música de animação, logo após ocorre o que eles 
chamam de momento de perdão, o coordenador do grupo vai à frente e discorre a respeito de arrependimento e pede a todos os participantes que pensem em seus pecados e erros cometidos ao longo da semana e orem por perdão, seguido por um momento de oração mais forte, onde todos os microfones ficam ligados e cada "servo" que se encontra na frente - ministério de música, ministério de pregação, coordenador etc.rezam uma coisa diferente do outro.

Neste momento foi observado que em todos os grupos, os servos e alguns participantes começam a orar em línguas. A glossolalia apresenta-se em uma característica marcante da Renovação Carismática Católica, conhecida como dom de línguas constitui-se basicamente em sons ininteligíveis, sem nexo, que de acordo com a crença católica ocorre em momentos de oração fervorosa quando o Espírito Santo está sendo clamado.

A glossolalia é um dos dons do Espírito Santo e pode ser considerado o dom mais difundido entre os fiéis. Tal oração é realizada para invocar o Espírito Santo, de acordo com a explicação da Renovação Carismática Católica, é também um momento em que os fiéis praticam um dos dons carismáticos. Como já foi falado, tais dons atraem os fiéis ao proporcionar-lhes a sensação de que estão atuando mais, possuem maior valor, e no momento acima descrito, é acreditado pelos fiéis que são os responsáveis por invocar o Espírito Santo através de suas orações.

Em uma tentativa de criar uma uniformidade entre os grupos de oração da Renovação Carismática Católica, todos os encontros ocorrem de acordo com uma mesma rotina, sendo que os temas trabalhados são definidos com uma semana de antecedência, portanto, o tema abordado em um grupo, é o mesmo abordado em todos os outros grupos de sua região. De acordo com as falas dos entrevistados, os temas são decididos em reuniões com os coordenadores onde os mesmos rezam pedindo uma indicação a Deus, entretanto a RCC possui livros com temas e sugestões para a realização dos encontros.

A respeito dos temas trabalhados nos grupos, todos são previamente estabelecidos para os coordenadores, os assuntos abordavam de forma geral questões a respeito de pecado, arrependimento, devoção e a vida religiosa, sendo o que mais chamou a atenção a carga de culpa e a constante demarcação das ações consideradas corretas, ou cristãs e as ações erradas, ou pecaminosas. 
Nos encontros observados, os temas debatidos foram, bem e mal, pecado e arrependimento, santidade e viver Deus, consecutivamente. Mesmo que com temas diferentes, os conteúdos das pregações apresentaram-se muito similares, em todos os monólogos dos pregadores eram constantemente abordadas questões a respeito da vida religiosa e da vida social, enfatizando a necessidade de abandonar - em suas palavras hábitos mundanos, como sair com os amigos para bares, festas e baladas, para poder viver de fato a vida cristã, seguir o caminho de Jesus.

Em todas as pregações estavam presentes e constantemente reforçadas, figuras como o demônio e o inferno, sendo referenciadas ao mundo e às pessoas fora da Igreja. Foi possível reparar a frequente afirmação de que é necessário para o jovem abrir mão de sair com os amigos para ir ao grupo, sendo que em alguns momentos foram feitas afirmações de que se algum amigo lhe convidasse a sair no horário do grupo, esta seria uma forma do Diabo afastar-lhes de Deus. Tais argumentos mostraram-se presentes em todos os discursos ouvidos nas observações e acabam por criar uma certa rivalidade entre os jovens dos grupos para com os demais de seus convívios sociais.

A exigência de uma abnegação da vida social em prol da Igreja não é utilizada somente para criar um afastamento entre os jovens religiosos e os não religiosos, tal questão é explorada, ainda, em outros dois sentidos. Primeiramente pretende incentivar a criação de vínculos de amizade entre os jovens frequentadores dos grupos e em segundo lugar instigá-los a trazer seus amigos para os encontros e consequentemente para a Igreja.

$\mathrm{Na}$ análise das entrevistas foi possível detectar que em todos os casos o contato dos jovens com a RCC foi proporcionado pelo convite e amigos e familiares, sendo que três deles vivenciaram o mesmo a partir de uma experiência de oração. As experiências de oração são basicamente encontros com fins espirituais, podem ocorrer tanto nas igrejas, quanto em retiros, está presente nas ações de evangelização e conversão da Renovação desde seu início no Brasil, sendo uma das primeiras formas de contato dos fiéis com este movimento nos tempos de seu surgimento. Através dos relatos foi possível perceber que as experiências de oração ainda possuem grande força na captação de novos fiéis.

Torna-se válido ressaltar que nos quatro casos os entrevistados afirmaram que apesar de terem se iniciado na Igreja Católica desde crianças, estavam afastados da 
Igreja, sendo que no decorrer das entrevistas três deles relataram estarem em situações, consideradas por eles, de autodestruição, ou que sentiam a necessidade de mudarem suas vidas. Os relatos de mudança de vida e salvação pela conversão à RCC são frequentes, em todos os encontros observados os coordenadores ou os pregadores convidados realizaram depoimentos aos fiéis, relatando o quanto suas vidas mudaram e, segundo eles, melhoraram.

Tais espécies de relatos são facilmente encontradas em depoimentos de fiéis de Igrejas Pentecostais e Neopentecostais, que têm como foco a salvação por meio da conversão. Essa é somente uma das características similares entre estes movimentos e a Renovação Carismática Católica, a qual possui eventos específicos neste aspecto, como os encontros de cura e libertação. Os relatos de mudanças nos estilos de vida reforçam um elemento extremamente presente no discurso tanto do movimento quanto de seus fiéis, a ideia do resgate, que pode ser observada na fala da um dos entrevistados já citada, que afirma sentir que salva uma alma cada vez que consegue trazer uma pessoa nova para os encontros de seu grupo de Oração.

A Renovação Carismática Católica encontrou na juventude um solo fértil para seus fiéis, possuindo elementos e características modernas, atua em diversos espaços e promove grandes eventos que atraem este nicho de fiéis. Em todas as entrevistas as percepções das respostas foram as mesmas, tornando possível analisar que a Renovação Carismática Católica tem conseguido atrair jovens provenientes de famílias católicas, mas que estavam com relações enfraquecidas com a Igreja. Um dos principais aspectos que mais aparenta agradar a juventude é a transformação nos ritos, tornando-os mais agradáveis aos jovens, mais dinâmicos, com um linguajar mais jovem e contemporâneo, nos encontros dos grupos de oração as relações se diferenciam das missas, tanto os coordenadores quanto os pregadores são leigos, tornando mais fácil para os participantes se identificarem com eles e suas falas.

A Renovação Carismática Católica trouxe consigo maiores possibilidades e espaços para a atuação dos fiéis, proporcionando neles uma sensação de maior participação e poder de ação, deixando de exigir somente a crença e a obediência, mas utilizando de maneiras diferentes a capacidade de interação de seus fiéis. Não somente os espaços de atuação dentro da estrutura da RCC, como coordenações, ministérios etc. que atraem e proporcionam uma sensação de maior participação, mas também, os dons 
carismáticos ou dons do Espírito Santo. O fato de se sentirem possuidores de dons e serem reconhecidos pelos mesmos, proporciona aos jovens não somente uma sensação de participar e agir, mas também um sentimento de importância, já que cada dom é incentivado e reconhecido por todos os integrantes.

Ainda, o que se pôde constatar, que além de todos os fatores acima citados, outro elemento de maior importância está presente na atração dos jovens por este movimento, o sentimento de pertença. Em todas as entrevistas foi possível reparar a utilização de termos como, família, amigos, amor, entre outros, ao serem mencionadas as relações estabelecidas com os demais participantes dos grupos.

Não é de hoje que se trabalha a importância do pertencimento na constituição de grupos entre os jovens, sejam religiosos, punk's, hippies, ou outros. Os jovens sempre procuraram espaços onde pudessem se sentir aceitos e correspondidos, locais onde houvesse a sensação de que pertencem, de estar entre iguais. Sendo este um dos principais fatores de agregação da juventude, a busca por uma identidade, uma identidade que possa defini-los ao mesmo tempo em que possa ser compartilhada. Em suma, uma busca por sua identidade individual, que seja aceita dentro de uma identidade de grupo.

[...] Em outras palavras, quando o assunto é a interpretação da conduta de um grupo religioso, a ideia que cada grupo faz de si mesmo é fundamental, sem descurar que boa parte dessa autoimagem comporta elementos que pertencem ao domínio inconsciente. Em síntese, metodologicamente falando, para se interpretar as motivações de um grupo, faz-se mister ir além do inventário de seus comportamentos e discursos num momento e/ou numa conjuntura dados; é preciso ainda elucidar os princípios não conscientes por meio dos quais o grupo constrói (coletivamente) a realidade.[...] (BITTENCOURT FILHO, 2003, p 195)

Uma vez encontrada essa identidade dentro de um grupo, diversas outras relações começam a se desenvolver, sendo que nos grupos de oração da Renovação Carismática Católica os jovens que ali estão não encontram somente um espaço de oração, mas também um local para a socialização com os demais, um espaço onde se criam laços de amizade e de companheirismo, proporcionando aos mesmos o sentimento de pertença. Este sentimento é entendido nesta pesquisa enquanto o 
principal fator mantenedor da juventude dentro da Renovação Carismática Católica, o fato dos jovens sentirem-se parte do movimento, com sua importância reconhecida acaba por melhor agregá-los. Ao ingressarem nos grupos da Renovação Carismática Católica os jovens estabelecem relações com os demais participantes, criando laços de amizade, estes relacionamentos agregam valor ao próprio movimento.

Em todas as entrevistas foi possível reparar a presença de afirmações que referenciando às relações estabelecidas entre os fiéis, utilizando termos como família e amigos, esta criação de laços e relacionamentos que proporcionam aos jovens sentiremse integrantes. Em busca de sua identidade os jovens buscam por grupos, e ao participarem dos grupos de oração da Renovação Carismática Católica acabam por criar redes de solidariedade com os demais participantes, encontrando suporte emocional.

A Renovação Carismática Católica tem alcançado, desde sua chegada ao Brasil, um amplo espaço para seu desenvolvimento. Após o Concílio Vaticano II e os embates promovidos pela Teologia da Libertação na América Latina, apresentou-se ao Vaticano enquanto um caminho a ser seguido, dado as suas transformações nos ritos e em suas ações. As alterações trazidas com ela apresentaram possuir certa popularidade entre a camada jovem dos fiéis, sendo que ao fazerem uso dos meios de comunicação social, como estações de rádio, canais de televisão além dos espaços virtuais da internet, conseguiram utilizar locais e linguagens de alta utilização juvenil. Os meios de comunicação social abriram maiores espaços para seu projeto evangelizador, por meio da inserção de conteúdos e ideais católicos.

Não obstante, sua penetração no mercado editorial e fonográfico não somente expande suas áreas de alcance, como também responde às demandas de consumo criadas com os novos perfis de fiéis. Esta é outra característica marcante deste movimento, oferece aos fiéis mercadorias, não somente religiosas, mas também bens de consumo que vão desde livros e CD's à bíblias estilizadas e joias, fator de atração, uma vez que está imersa em uma sociedade de consumo.

No tocante à juventude, suas ofertas de consumo, de práticas e vivências religiosas mostram-se como fortes fatores para cativar seus participantes; entretanto, o que é importante ressaltar é a oferta de um espaço religioso de convivência que é utilizado também para a criação de relações pessoais e principalmente a formação de um grupo. $\mathrm{O}$ ato de vincular-se a um grupo está diretamente ligado à busca dos jovens 
por sua identidade, sendo a juventude uma etapa em que os indivíduos se encontram em processo de formação, filiar-se à Renovação Carismática Católica é também uma procura por espaços de construção de uma identidade e de socialização.

\section{Considerações Finais}

O sentimento de pertencimento encontrado pelos jovens e todas as relações que dele derivam, na Renovação Carismática Católica, pode ser analisado enquanto principal elemento de atração e agregação da juventude. Os jovens encontram-se em um constante processo de construção de sua identidade, em busca de espaços para expressar-se e sentirem-se acolhidos e compreendidos. Não é somente o grupo de oração em si que proporciona tais elementos aos jovens, mas sim as partes que os integram.

Ao entrar em um grupo de oração são encontrados diversos outros jovens, os quais possuem uma predisposição de acolher novos integrantes, assim como estão em busca de sua identidade e do pertencimento, a religiosidade acaba por constituir-se enquanto fator comum para empatia dos mesmos, mas os laços sociais ali criados apresentam-se enquanto principal fator de agregação.

\section{Referenciais}

BENEDETTI, Luiz Roberto. Entre a crença coletiva e a experiência individual: renascimento da religião. In.: ANJOS, Márcio Fabri dos. Sob o fogo do espírito. São Paulo, Paulinas, 1998.

Templo, Praça, Coração, Tese doutorado, São Paulo, USP, 1998.

BITTENCOUR FILHO, José. Matriz Religiosa Brasileira: religiosidade e mudança social. Petrópolis, RJ: Vozes: Petrópolis; Rio de Janeiro: KOINONIA, 2003.

BOURDIEU, Pierre. A economia das trocas simbólicas. 5 ed. São Paulo: Perspectiva, 2004.

BITTENCOUR FILHO, José. Matriz Religiosa Brasileira: religiosidade e mudança social. Petrópolis, RJ: Vozes: Petrópolis; Rio de Janeiro: KOINONIA, 2003.

BRASIL 2013. Estatuto da Juventude. Ministério da Justiça, Brasília.

CARRANZA, Brenda. Renovação carismática católica: origens, mudanças e tendências. Aparecida: Editora Santuário, 2000. 
MAFFESOLI, Michel. O tempo das Tribos: o declínio do individualismo nas sociedades de massa. RJ: Forense Universitária, 1987.

MARIZ, Cecília Loretto. A Renovação Carismática Católica No Brasil: uma revisão da bibliografia. In.: RODRIGUES, Donizete (org.). Em Nome de Deus: a religião na sociedade contemporânea. Porto: Edições Afrontamento, 2004, PP. 169-183.

NOVAES, Regina. Os jovens de hoje: contextos, diferenças e trajetórias. In: ALMEIDA, Maria Isabel Mendes de, EUGENIO, Fernanda (orgs.), Culturas Jovens: novos mapas do afeto. Rio de Janeiro: Jorge Zahar Ed., 2006, p.105-120.

PIERUCCI, Antônio Flávio. Bye Bye, Brasil - O Declínio das Religiões Tradicionais no Censo 2000, in Estudos Avançados, v. 18, n. 52, 2004.

PIERUCCI, Antonio Flávio e PRANDI, Reginaldo. A realidade social das religiões no Brasil. São Paulo, Hucitec, 1996.

PRANDI, Reginaldo. Um sopro do espírito. São Paulo: Editora da Universidade de São Paulo: Fapesp, 1998.

SOFIATI, Flávio Munhoz. Religião e Juventude: os novos carismáticos. Aparecida, Idéias \& Letras, São Paulo, Fapesp, 2011.

A Juventude no Brasil: história e organização. Passages de Paris (APEB-Fr), v. 2008, p. 1-14, 2008.

Recebido: 22/09/2016

Received: 09/22/2016

Aprovado: 11/10/2016

Approved: 10/11/2016 